\title{
A study of the Repeated Actions Diary in patients suffering from obsessive compulsive disorder
}

\author{
Martine Bouvard ${ }^{1,2}$ (- | Nathalie Fournet ${ }^{1,2}$ | Anne Denis ${ }^{3,2}$ ( \\ Ouafae Achachi $^{1,4}$ | Christine Purdon ${ }^{5}$
}

${ }^{1}$ Psychology and neurocognition laboratory, Univ. Grenoble Alpes, Univ. Savoie Mont Blanc, CNRS, LPNC, Grenoble, France

${ }^{2}$ Department of psychology, Savoie Mont Blanc University Psychology Centre, Chambéry, France

${ }^{3}$ LIP/PC2S, Univ. Grenoble Alpes, Univ. Savoie Mont Blanc, LIP/PC2S, Grenoble, France

${ }^{4}$ Hospital, Clinea (Lyon Lumière), Meyzieu, France

${ }^{5}$ Department of Psychology, University of Waterloo, Waterloo, Ontario, Canada

\section{Correspondence}

Martine Bouvard, Univ. Grenoble Alpes, Univ. Savoie Mont Blanc, CNRS, LPNC, 38000

Grenoble, France.

Email: martine.bouvard@univ-smb.fr

Funding information

SFR Santé et Société, University Grenoble Alpes, France

This is the peer reviewed version of the following article: Bouvard, M., Fournet, N., Denis, A., Achachi, O., \& Purdon, C. (2020). A study of the Repeated Actions Diary in patients suffering from obsessive compulsive disorder. Clinical

Psychology \& Psychotherapy, 27(2), 228-238. https://doi.org/10.1002/cpp.2422, which has been published in final form at https://doi.org/10.1002/ cpp.2422. This article may be used for noncommercial purposes in accordance with Wiley Terms and Conditions for Use of Self-Archived Versions.
The structured Repeated Action Diary (RAD) collects in vivo data on compulsions and their various characteristics. Certain compulsions (i.e., those ending because the patient feels certain that it is safe to stop) are then compared with uncertain compulsions. The compulsion profile in patients with obsessive compulsive disorder (OCD) was assessed by using the RAD. Thirty-two patients from two sources participated in the study. Before pooling the two subgroups, we checked that they did not differ significantly with regard to demographic and clinical variables. Patients reported several categories of compulsion. The most frequently reported compulsions were washing and checking. In a given person, checking compulsions (in contrast to washing compulsions) were often produced by several different obsessions. Almost all the patients reported repeating the compulsions because of a need to feel sure. There were far more "certain" compulsions than "uncertain" compulsions. The number of repetitions was significantly lower for certain compulsions than for uncertain compulsions. The person felt greater relief from guilt and responsibility and a greater decrease in discomfort at the end of a compulsive episode for certain compulsions than for uncertain compulsions. In conclusion, the need to ritualize (prompted by uncertainty, i.e., potential danger) might explain the maintenance (or posttreatment recurrence) of OCD in many patients. The need for certainty in the completion of a compulsion may be worth considering as a therapeutic tool. The development of an approach based on the need for certainty might help to improve treatment outcomes.

\section{KEYWORDS}

compulsions, intolerance for uncertainty, obsessive compulsive disorder, Repeated Action Diary

\section{1 | INTRODUCTION}

Obsessions provoke anxiety or distress. Compulsions are aimed at preventing or reducing the obsessions' anxiety-inducing effect (American Psychiatric Association, 2013). In contrast to compulsions, obsessions and their associated beliefs have been extensively studied. The resulting body of knowledge has refined our understanding of obsessive compulsive disorder (OCD). Individuals with $O C D$ frequently report uncertainty or doubt as to whether they have performed actions correctly or have touched objects that may be contaminated (Purdon, 2018). To reduce the level of doubt, patients perform mental or motor compulsions, such as checking, washing, and repeating (Tolin et al., 2001). Compulsive washing can be motivated by harm avoidance (wanting to decontaminate), incompleteness (wanting to feel "just right"), or "mental contamination" (Coughtrey, Shafran, Knibbs, \& Rachman, 2012; Rachman, 2004) transmitted and spread in the absence of physical contact with a contaminant (Coughtrey et al., 2012; Ishikawa, Kobori, \& Shimizu, 2014; Mathes, 
McDermott, Okey, Vasquez, Harvey, Cougle, 2019). Feelings of mental contamination can be prompted by thinking about dirt or remembering immoral events, undesirable people, or unpleasant things or events (Coughtrey, Shafran, \& Rachman, 2004; Mathes et al., 2019). If the person does nothing, the feeling of being mentally contaminated decreases over time. In contrast, if the triggering thoughts reoccur and the person engages in washing behaviour, the feeling is maintained. Ecker and Gönner (2008) found that symmetry/ordering rituals were a significant predictor of incompleteness and that checking rituals were significant predictors of harm avoidance and incompleteness. Rachman (2002) considers that responsibility has a critical role in checking but not in obsessions and that checking is maintained by four factors: (a) paradoxical increases in perceived responsibility, (b) paradoxical increases in the perceived probability of harm, (c) reduced confidence in memory, and (d) an unsuccessful search for a certain end to the threat (Rachman, 2002).

Compulsions have been described as safety-related behaviours that maintain the problem (Rachman, Radomsky, \& Shafran, 2008) or as security-related behaviours (Hinds, Woody, Van Ameringen, Schmidt, \& Szechtman, 2012). Szechtman and Woody (2004) proposed that OCD is a dysfunction of a biologically primal motivational system that helps an individual to protect herself or himself from potential dangers (such as diseases and accidents). According to this model, OCD is a disorder of the security motivation system (Woody \& Szechtman, 2011, 2013). Hinds, Woody, Van Ameringen, Schmidt, and Szechtman (2012) postulated that OCD is a problem of stopping, rather than starting. The researchers monitored respiratory sinus arrhythmia (the normal increase in heart rate that occurs during inspiration) as a measure of the degree of security motivation. The results showed that (a) washers did not display heightened initial sensitivity (relative to nonclinical subjects) to a potential threat and (b) OCD patients were less able to use security-related behaviour to terminate washing. In the latter case, the individual's lack of confidence in his or her judgment means that the compulsion persists until it feels "just right."

A number of studies have directly examined the impact of repeated checking on memory accuracy and confidence in nonclinical samples. For instance, van den Hout and Kindt (Van den Hout \& Kindt, 2003; Van den Hout \& Kindt, 2004) observed that 20 trials of repeated checking did not alter memory accuracy but did degrade memory confidence, memory vividness, and memory details. Moreover, repeated checking was associated with a shift in the memory source from "remembering" (i.e., explicit recall of the details of an event) to "knowing" (i.e., a sense of familiarity but without remembering the details; Tulving, 1985). Repeated checking increases familiarity with the checked issues, which in turn promotes conceptual processing ("knowing") and inhibits perceptual processes ("remembering"). These results have been replicated in OCD patients (Coles, Radomsky, \& Horng, 2006; Radomsky, Gilchrist, \& Dussault, 2006) and in healthy volunteers engaged in a virtual checking task (van den Hout, van Dis, van Woudenberg, \& van de Groep, 2019). Hence, the decline in memory confidence with repeated checking is a normal phenomenon.

\section{Key Practitioner Message}

- Practitioners are invited to collect, via the structured Repeated Action Diary, in vivo data on compulsions and their various characteristics.

- The diary helps practitioners to define two types of compulsions as a function of their stop criterion: a "successful compulsion" (i.e., a certain episode, when the patient considers that it is okay to stop) and an unsuccessful compulsion (i.e., an uncertain episode).

- The certain compulsion (successful compulsion) was effective in reassuring the patient and would explain the persistence of compulsion.

- The need for certainty in the completion of a compulsion may be worth considering as a therapeutic tool.

Starcevic et al. (2011) used the Functions of Compulsions Interview to determine why people with OCD executed their compulsions; the researchers found that the great majority of compulsions (85.3\%) had several apparent justifications. Compulsions were most frequently carried out automatically (71.6\%) or to decrease levels of distress or anxiety (62.4\%). The functional value depended on the type of compulsion. Ordering/repeating compulsions were frequently produced to achieve a "just right" feeling. Checking compulsions were performed because of the belief that something bad would happen. Washing/cleaning compulsions were automatically carried out to decrease distress. Lastly, mental compulsions were performed automatically far more often than other types of compulsions. Most studies of compulsions have relied on self-reports or on laboratory paradigms designed to evoke compulsion-like behaviour. In contrast, very few studies have observed compulsions in everyday life. Bucarelli and Purdon (2015) used the structured Repeated Action Diary (RAD) to perform a "real-life" study of compulsions (Purdon \& Bucarelli, 2010). The diary enables patients to report on the occurrence and characteristics of compulsive episodes three times a day during a 3-day period. It includes items with closed questions (e.g., "How awful would the consequences of not performing the compulsion have been?") and items with open questions ("What was the compulsive act?"). The patient records obsessions and compulsions and then rates (a) the discomfort caused by the obsession, (b) the severity of the consequences of not performing the compulsion, and (c) the degree of certainty needed to complete the compulsion "properly." Next, the patient rates the compulsion parameters, including the compulsive episode's duration and the number of repetitions during the episode. Four questions focus on the events after the compulsion and, more precisely, on the level of relief afforded by the compulsion (general relief, reduction in guilt, reduction in responsibility, and reduction in distress). For repeated compulsions, the subject also rates the influence of repetitions on (a) senses, memory, attention, and cognitive confidence, (b) the amount and range of evidence required in order to 
determine whether a compulsion had been completed "properly" (the need to attend to more details and the need for more evidence that it had been performed correctly), and (c) the level of the certainty (in terms of memory and attention) as to whether the said compulsion had been completed "properly." Lastly, the subject ranks the criteria for stopping (internal criteria, feeling completely certain that it was okay to stop; feeling certain enough that it was okay to stop; achieving the "right feeling"; or stopping in response to external or other demands). If the patient ranked "I was completely certain that it was okay to stop," "I was certain enough it was okay to stop," or "I got the right feeling" as one of the top two reasons for stopping, then the compulsion was considered to be successful (i.e., a certain compulsion; Bucarelli \& Purdon, 2015). To summarize the self-reports in the RAD cover the duration and number of compulsions, the number of repetitions, events prior to compulsion (obsession, distress, the supposedly awful consequences of not performing the compulsion, and the need for certainty that the compulsion will be performed properly), events during the compulsion (erosion of memory, attention, cognitive confidence, and increases and decreases in certainty that the compulsion has been executed properly), and events after the compulsion (relief afforded by the compulsion). Analysis of the RAD results helps to identify "certain" compulsions and "uncertain" compulsions. A certain compulsion is one that ends because the individual feels certain that is "okay" or "safe" to stop, whereas an uncertain compulsion ends for other reasons. In Bucarelli and Purdon study (2015), certain compulsions accounted for $53 \%$ of the compulsive behaviours. In other words, more than half the compulsions were effective in reassuring the patients. Levels of confidence in general memory and cognitive ability were associated with "successful" (i.e., certain) compulsions. Uncertain compulsions were associated with greater repetitions, poorer in vivo confidence in memory and in cognitive and sensory processes, an increase in the amount of evidence required to take the decision to stop, and less relief. The study's results showed that (a) a sense of certainty has an important role in deciding when to stop a compulsion and (b) OCD patients perceived their compulsions to be effective. Evidencing these two types of compulsions would improve our understanding of the disorder. Hence, we reasoned that examining compulsions in daily life might provide insight into why they were maintained. With a view to explaining the persistence of OCDs, the beliefs associated with obsessions have been extensively studied (e.g., Adams, Riemann, Wetterneck, \& Cisler, 2012; Diedrich et al., 2016; Salkovskis, Shafran, Rachman, \& Freeston, 1999). There are fewer literature data on the persistence of compulsions, however. Abramowitz, Franklin, and Cahill (2003) looked at factors that favoured the persistence of compulsions, such as intolerance of uncertainty. This cognitive bias (an error of logic) might be specific for OCD-relevant situations. Compulsions may thus be considered as attempts to be completely certain that a catastrophe will be avoided (Abramowitz, Franklin, \& Cahill, 2003). Jacoby, Reuman, Blakey, Jeremiah Hartsock, and Abramowitz (2019) evidenced the importance of this bias in nonclinical cases placed in a situation where they were responsible for the negative consequences of their decision on others (Jacoby, Reuman, Blakey, Hartsock, \& Abramowitz, 2019).
The objective of the present study was to use Purdon and Bucarelli's RAD (2010) to assess and compare compulsions in patients with OCD. The RAD is of value because it provides a description of a compulsion in everyday life (from the reasons for its generation to the reasons for cessation). The diary's disadvantage is that only a limited number of compulsions can be reported. The primary objective of the present study was to assess the compulsion profile in an OCD group. The secondary objective was to compare certain compulsions (i.e., those ending because the patient feels certain that it is safe to stop) with uncertain compulsions (those ending for other reasons). The certain compulsion was effective in reassuring the patient, so it was considered to be successful (Bucarelli \& Purdon, 2015) and would explain the persistence of compulsions.

\section{2 | METHODS}

\section{1 | Participants}

The participants were recruited at two different sites. Sixteen patients in the "relapsing OCD" (R-OCD) subgroup had undergone at least one full course (and often two courses) of cognitive behavioural therapy (CBT) and were in a private clinic to receive further treatment. Sixteen "treatment-naïve-OCD" (TN-OCD) patients had either never undergone a course of CBT or were in the early stages of psychotherapy. Hence, 32 patients participated in the study. Given that the two subgroups of patients had come from different care pathways, we checked for the absence of significant intergroup differences in all the demographic and clinical variables studied (including the RAD scores) before pooling them. All had a confirmed, primary diagnosis of OCD. The R-OCD and TN-OCD subgroups did not differ significantly in terms of the gender ratio $\left(X^{2}=0.13 ; p=.709\right)$, mean $(S D)$ age (37.93 (11.83) vs. 35.12 (8.03) years, respectively; $t=0.78 ; p=.437$ ), mean educational level (13.75 (2.46) vs. 15.12 (3.57) years of full-time education, respectively; $t=1.26 ; p=.214$ ), or the mean duration of OCD (19.00 (12.99) vs. 16.00 (9.77) years, respectively; $t=0.73 ; p=.737$ ). In each of the two subgroups, six patients were taking antidepressants or other medications for their OCD, and 10 were not. Co-morbidity and OCD were evaluated using the Mini International Neuropsychiatric Interview (Lecrubier et al., 1997). The co-morbidity profiles were similar in the two subgroups $\left(X^{2}=0.53 ; p=.465\right) ; 11 \mathrm{TN}-\mathrm{OCD}$ patients and nine R-OCD patients had co-morbid disorders.

\section{$2.2 \mid$ Measures}

The Mini International Neuropsychiatric Interview (Lecrubier et al., 1997) is a semistructured clinical interview for the assessment of major disorders in the Diagnostic and Statistical Manual of Mental Disorders, fourth edition. Its psychometric properties are similar to those of the Structured Clinical Interview for Diagnostic and Statistical Manual of Mental Disorders, fourth edition (Lecrubier et al., 1997; Sheehan et al., 1998).

The Vancouver Obsessional Compulsive Inventory (Thordarson et al., 2004) is a 55-item, self-reporting instrument designed to 
evaluate a broad spectrum of OCD symptoms. It is composed of six subscales (checking, contamination, obsessions, hoarding, "just right" feelings, and indecisiveness) and has good psychometric properties (Cronbach's $\alpha$ : .93).

The Memory and Cognitive Confidence Scale (MACCS; Nedeljkovic \& Kyrios, 2007) is a revised, shortened version of the Confidence in Memory Scale. The four subscales assess (a) beliefs about general memory abilities, (b) confidence in decision-making abilities, (c) confidence in one's ability to concentrate, and (d) high standards with regard to one's cognitive performance. The MACCS has demonstrated good test-retest reliability and internal consistency in clinical, student, and community samples (Cronbach's $\alpha$ : .93).

The French version of the Obsessive Beliefs Questionnaire (OBQ-44; Julien et al., 2008) was used to assess OCD-related beliefs. The 44-item OBQ has three subscales: (a) responsibility and overestimation of threat, (b) perfectionism and uncertainty, and (c) importance and control of thoughts. Cronbach's $\alpha$ was.95.

The Beck Depression Inventory (BDI; Beck, Ward, Mendelson, Mock, \& Erbaugh, 1961) indicates the intensity of depression. The French version of the BDI has been validated in a group of university students (Bourque \& Beaudette, 1982).

The RAD (Purdon \& Bucarelli, 2010) is a structured diary that enables people to report on their compulsive episodes three times a day (every morning, afternoon, and evening) for three consecutive days (i.e., nine entries in all). The diary captures in vivo data on both certain compulsions and uncertain compulsions (as described above).

\section{3 | Procedure}

All patients were provided with information on the study and gave their written, informed consent to participation. At the start of the study, an investigator reviewed all the questions in the diary with each patient. The investigator emphasized the importance of completing the diary as soon as possible after the compulsion had occurred. An appointment was scheduled for 7 days later, at which time the patient would return the diary and be debriefed. The patients in the R-OCD subgroup were recruited from the active case file of a private clinic (Clinea, Meyzieu, France), and the patients in the TN-OCD subgroup were recruited from the Savoie Mont Blanc University Psychology Centre (Chambéry, France). The study was approved by the independent ethics committee at the University of Savoie Mont Blanc (Chambéry, France; approval reference: 20146; approval date: February 25, 2014). The authors assert that all the study procedures complied with the ethical standards of the 1975 Declaration of Helsinki and its most recent revision.

\section{3 | RESULTS}

\section{1 | The self-questionnaires}

The mean $(S D)$ scores for all the questionnaires and their subscales are presented in Table 1. There were no differences between the R-OCD and TN-OCD subgroups with regard to obsessive compulsive

TABLE 1 Clinical characteristics of the participants

\begin{tabular}{|c|c|c|c|c|}
\hline & \multirow{3}{*}{$\begin{array}{l}\text { TN-OCD } \\
n=16 \\
M(S D)\end{array}$} & \multirow{2}{*}{$\begin{array}{l}\text { R-OCD } \\
n=16\end{array}$} & \multirow[b]{3}{*}{$\mathbf{t}$} & \multirow[b]{3}{*}{ p } \\
\hline & & & & \\
\hline & & $M(S D)$ & & \\
\hline Vancouver Obsessive Compulsive Inventory total & $90.68(32.41)$ & $91.87(40.13)$ & -0.09 & .920 \\
\hline Checking & $22.62(10.30)$ & $24.00(9.85)$ & -0.38 & .702 \\
\hline Contamination & $27.75(14.07)$ & $16.25(11.54)$ & 2.52 & .017 \\
\hline Obsessions & $6.68(7.71)$ & $7.56(8.50)$ & -0.30 & .762 \\
\hline Hoarding & $13.43(9.62)$ & $19.43(12.18)$ & -1.54 & .132 \\
\hline Just right & $9.68(8.24)$ & $12.93(7.23)$ & -1.18 & .245 \\
\hline Indecisiveness & $10.50(5.35)$ & $11.68(5.47)$ & -0.62 & .539 \\
\hline Obsessive Belief Questionnaire total & $182.25(60.10)$ & $175.31(53.88)$ & 0.34 & .733 \\
\hline Responsibility/overestimation of threat & $70.06(26.66)$ & $71.68(27.19)$ & -0.17 & .865 \\
\hline Perfectionism/uncertainty & $71.50(22.45)$ & $62.56(21.91)$ & 1.13 & .263 \\
\hline Importance and control of the thought & $40.68(20.73)$ & $41.06(20.01)$ & -0.05 & .958 \\
\hline Beck Depression Inventory & $16.66(8.41)$ & $19.06(8.80)$ & -0.77 & .445 \\
\hline Memory and Cognitive Confidence Scale total & $83.56(20.12)$ & $84.56(23.24)$ & -0.13 & .897 \\
\hline Beliefs about general memory abilities & $40.00(13.35)$ & $40.25(16.15)$ & -0.04 & .962 \\
\hline Confidence in decision-making abilities & $16.37(4.41)$ & $17.50(3.50)$ & -0.79 & .430 \\
\hline Confidence in one's ability to concentrate & 12.25 (3.69) & $12.87(4.55)$ & -0.42 & .673 \\
\hline High standards about one's cognitive performance & $14.93(2.71)$ & $13.93(3.37)$ & 0.92 & .363 \\
\hline
\end{tabular}

Note. Bonferroni correction $p<.05 / 17=.002$.

Abbreviations: R-OCD, relapsing obsessive compulsive disorder; TN-OCD, treatment-naïve-obsessive compulsive disorder. 
symptoms (Vancouver Obsessional Compulsive Inventory), obsessive compulsive beliefs (OBQ-44), the intensity of depression (BDI), and obsessive compulsive metacognitions (MACCS).

\section{2 | Compulsions in everyday life}

Prior to the analyses of the RAD, average single and aggregate variables were created by summing them and dividing by the number of total entries. Averages were obtained for each patient by summing the variables for "certain" and for "uncertain" compulsions and then dividing the sum by the corresponding number of episodes of compulsion. As expected, the two subgroups' RAD scores were similar with regard to events prior to the compulsion, compulsion characteristics, and events after compulsion (Table 2). The same was true for the impact of repeated compulsions on doubt (the senses and attention), certainty (memory and attention), evidence requirements, and the perceived length of the episode.

The two subgroups were similar with regard to all the variables measured during a compulsion (Table 3 ). The participants in the ROCD subgroup reported as many compulsions as the participants in the TN-OCD subgroup. Almost all the compulsions resulted from an obsession. In the R-OCD subgroup, $96 \%$ of compulsions were preceded by an obsession, whereas this was the case for $91 \%$ of the compulsions in the TN-OCD subgroup. Most patients reported that the compulsion was the same as the obsession (e.g., washing caused by a fear of contamination). A number of different obsessions led to the same compulsion (e.g., checking was variously preceded by fear of causing an accident, fear of being attacked, fear of making a mistake, and fear of catching a disease). In general, patients reported several categories of compulsions, rather than just one. Overall, the most frequent compulsions were washing and checking. Some patients reported that repeating was a means of cancelling the "fear that something bad would happen" obsession. The need to feel that things were perfect led to a house-tidying compulsion is scarce in our group. Compulsive washing was generally preceded by a "contamination" or "dirt" obsession. Checking compulsions had several causal obsessions (i.e., fear of making a mistake, fear of harming someone or fear of causing an accident, fear that something bad would happen, and fear of catching a disease). Fifteen patients in the R-OCD subgroup reported 75 (57\%) repeated compulsions, and 15 patients in the TNOCD subgroup reported 74 (55\%) repeated compulsions. The main

TAB LE 2 The RAD scores for compulsion-related parameters

\begin{tabular}{|c|c|c|c|c|}
\hline & $\frac{\mathrm{TN}-\mathrm{OCD}}{\mathrm{M}(\mathrm{SD})}$ & \multicolumn{2}{|l|}{ R-OCD } & $\mathrm{p}$ \\
\hline \multicolumn{5}{|l|}{ Events prior to compulsion } \\
\hline Distress from obsession & $5.80(0.49)$ & $6.13(0.47)$ & 90.50 & .064 \\
\hline Awful consequences of not performing the compulsion & $5.81(0.72)$ & $5.93(0.79)$ & 132.50 & .691 \\
\hline A need to be certain (prior) & $5.93(0.83)$ & $5.99(0.95)$ & 141.50 & .931 \\
\hline Length (min) & $29.63(30.52)$ & $17.96(13.90)$ & 118.00 & .369 \\
\hline Number of repetitions & $7.71(13.06)$ & $4.57(5.83)$ & 131.50 & .666 \\
\hline \multicolumn{5}{|l|}{ Events after compulsion } \\
\hline General relief & $5.98(0.68)$ & $5.87(0.83)$ & 131.50 & .666 \\
\hline \multicolumn{5}{|l|}{ The more the compulsion is repeated } \\
\hline The more I doubt my senses & $3.64(2.05)$ & $4.21(1.71)$ & 108.50 & .649 \\
\hline The more I doubt my memory & $3.17(1.99)$ & $4.27(1.40)$ & 85.00 & .166 \\
\hline The more I doubt my attention & $4.02(1.26)$ & $4.62(1.29)$ & 84.50 & .160 \\
\hline Confidence that it had been conducted properly & $4.67(1.10)$ & $4.05(1.35)$ & 83.00 & .143 \\
\hline The need to attend to more details & $4.54(1.11)$ & $4.43(1.20)$ & 113.50 & .797 \\
\hline $\begin{array}{l}\text { Need for more evidence that it had been performed } \\
\text { correctly }\end{array}$ & $3.93(1.48)$ & $4.21(1.46)$ & 104.50 & .540 \\
\hline The longer it took & $4.63(1.62)$ & $4.88(1.04)$ & 107.00 & .607 \\
\hline
\end{tabular}

Note. Bonferroni correction $p<.05 / 19=.002$.

Abbreviations: RAD, Repeated Action Diary; R-OCD, relapsing obsessive compulsive disorder; TN-OCD, treatment-naïve-obsessive compulsive disorder. 
TABLE 3 Qualitative data of the RAD

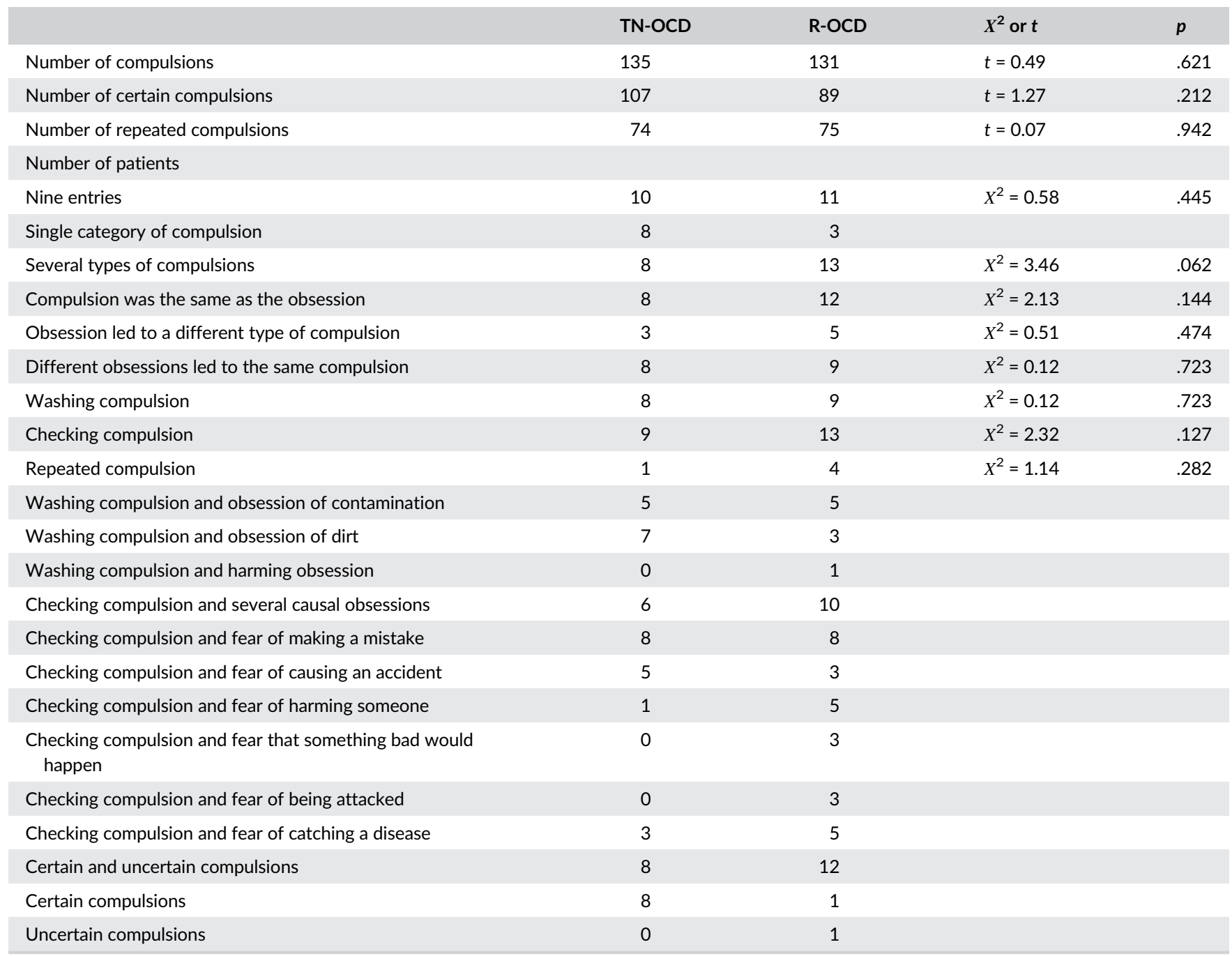

Note. Bonferroni correction $p<.05 / 24=.002$.

Abbreviations: RAD, Repeated Action Diary; R-OCD, relapsing obsessive compulsive disorder; TN-OCD, treatment-naïve-obsessive compulsive disorder.

reason (according to $85.13 \%$ of $\mathrm{TN}-\mathrm{OCD}$ patients and $85.33 \%$ of the R-OCD patients) for repeating a compulsion was the need to feel certain. Lastly, the R-OCD subgroup reported a total of 89 (67\%) certain compulsions, and the TN-OCD subgroup reported 107 (79\%).

Bonferroni's correction was used to adjust for multiple comparisons of the two types of compulsion (certain vs. uncertain). The threshold for statistical significance was set to $p<.05 / 9$ (=.005). The comparison of certain versus uncertain compulsions showed that the number of repetitions were significantly lower for certain compulsions than for uncertain compulsions (Table 4). There were no significant differences with regard to the level of discomfort caused by an obsession, the consequences of not executing a compulsion, the need to be sure that the compulsion would be performed correctly, or the duration of the compulsion. In contrast, there was a statistically significant difference in the level of relief afforded by the compulsion. In the case of a successful (certain) compulsion, the level of overall relief was greater, and the patient gained greater relief from guilt and responsibility and experienced a greater decrease in discomfort at the end of a compulsive episode.

\section{DISCUSSION}

The objective of the study was to examine compulsions in everyday life. There were no significant differences between the subgroups with regard to all the variables studied. Hence, we pooled the two subgroups for the purposes of the present analysis. The vast majority (>90\%) of the compulsions followed on from an obsession (i.e., with the goal of reducing anxiety or distress); this is in line with the data presented by Starcevic et al. (2011). In contrast to the participants in Starcevic and colleagues' study (2011), (a) none of our patients reported compulsions that had occurred automatically and (b) our patients recorded obsessions and compulsions and then evaluated the characteristics of the compulsions only; hence, only one reason (rather than several) could be noted. Overall, the most frequently reported compulsions were washing and checking. A few patients mentioned the need to feel that things were perfect as the reason for house-tidying, which they considered to be a compulsion.

Patients reported several categories of compulsion; indeed, few patients had a single category of compulsion. In some cases, a given 
TAB LE 4 Comparison of certain compulsions versus uncertain compulsions

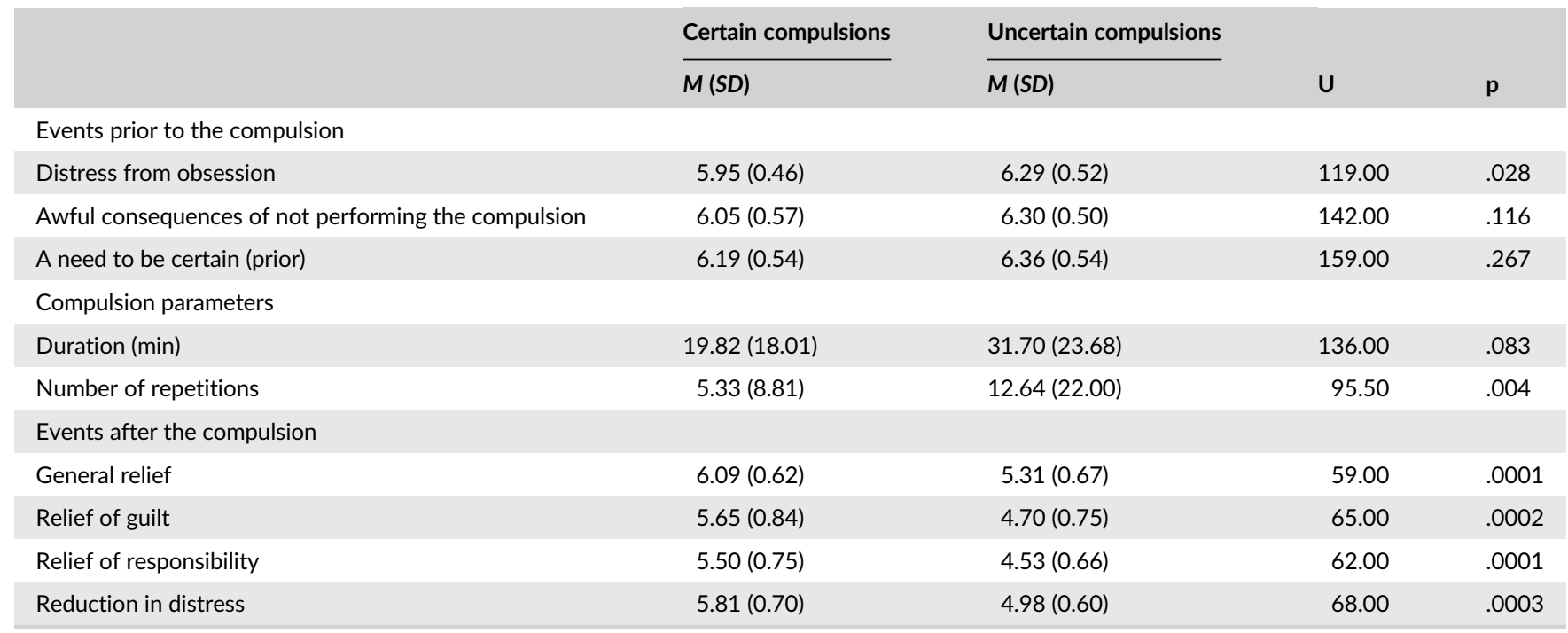

Note. Bonferroni correction $p<.05 / 9=.005$.

obsession could give rise to different compulsions. Conversely, different obsessions could give rise to the same compulsion. Compulsive washing can be motivated by fear of contamination and dirt. Checking rituals can be motivated by fear of making a mistake, fear of causing an accident, fear of harming someone, fear that something bad would happen, fear of being attacked, and fear of being contaminated and catching a disease. In our study population, checking compulsions (in contrast to washing compulsions) in a given person were often produced by several different obsessions. Some washing/cleaning compulsions (fear of dirt) were generated to decrease distress, whereas others (fear of contamination) were generated to avoid a negative event (harm avoidance). In line with Starcevic and colleagues' results (2011), checking compulsions were performed because of the belief that something bad would happen and most compulsions were performed to reduce anxiety or distress. A few patients repeated compulsions in order to avoid bad events (fear of bringing bad luck). The link between obsession and compulsion appears to be highly idiosyncratic.

Our first highly interesting finding was that almost all the patients (15 out of 16 in each group) reporting repeating compulsions because of a need to feel sure. The R-OCD and TN-OCD groups reported nearly the same number of repeated compulsions. The main reason for repeating was the need to feel certain ( $85 \%$ in both groups). The majority of patients terminated the compulsion when they were certain that "there is no danger." These findings are consistent with the literature data on the stopping rules for compulsions (internal feelings; Cougle, Goetz, Fitch, \& Hawkins, 2011) and the theory developed by Rachman (2002).

However, a "repetition" of a compulsion is difficult to define; if I spend 30 min watching a door to check that it is closed, does that count as a repetition? For some patients, a compulsion may last for $30 \mathrm{~min}$, whereas others may repeat a compulsion 50 times during the same period. The duration of a compulsion is also sometimes defined subjectively. In future research, it will be important to examine the exact duration and the number of repetitions more precisely.
Our second most interesting finding was that far more of the compulsions were "certain" (79\% in the TN-OCD group and $67 \%$ in the R-OCD group) than "uncertain." The "necessity" criterion (being certain that it was okay to stop or getting the right feeling) was most frequently reported criterion for stopping the compulsion, that is, the patient was certain that the situation no longer presented a risk. The comparison of certain (successful) compulsions with uncertain compulsions showed that (a) the number of repetitions were significantly lower for certain compulsions than for uncertain compulsions and (b) the person felt greater relief after executing that compulsion. More precisely, the person felt greater relief from guilt and responsibility and a greater decrease in discomfort for certain compulsions than for uncertain compulsions. It seems that in terms of the events prior to compulsion and the compulsion's parameters, only the number of repetitions can differentiate between successful and unsuccessful compulsions. In contrast, the feeling experienced after a certain compulsion differs from that experienced after uncertain compulsions. This might explain the maintenance of the compulsions. Our findings are similar to those reported by Bucarelli and Purdon (2015) and emphasize the value of observing compulsions. Some researchers consider that compulsions are related to safety (Rachman, Radomsky, \& Shafran, 2008) or security (Hinds et al., 2012). The proportion of certain compulsions observed in the present study was considerably higher than that in Bucarelli and Purdon's study (2015). This finding suggests that the extent to which compulsions reliably achieve their goals must be determined in larger studies. Our present results also suggest that compulsions are effective (most of the time) in reducing doubt-even when repeated. In $85 \%$ of reports, a need to feel sure was given as the reason for repetition. It suggests that (a) the ironic effect of repetition on memory confidence and certainty is not always present in real life and (b) other factors influence the termination of compulsions. These data are consistent with Hinds et al.'s (2012) view that OCD is a pathology of stopping, rather than starting. 
One limitation of the present study relates to the small number of diary entries. The RAD has only nine entries (three per day for three consecutive days); this is undoubtedly not enough to identify all the individual's compulsions. The RAD results are based on self-reporting, and there are no quality controls-especially with regard to the duration and the number of repetitions. In contrast, the RAD records reallife observations, rather than recalled compulsions. Ideally, all compulsions over a 1-week period should be recorded; this would probably better reflect the compulsions occurring in an individual's everyday life. This kind of real-life study could be facilitated by technological tools (e.g., smartphones). The current version of the RAD needs to be improved for better data collection. We suggest a revision of the RAD in which (a) the questions are given in a different order and (b) the participant answers all the questions, regardless of the type of compulsion. At present, the participant only answers the various questions on his or her feelings during the compulsion in the cases of a repeated compulsion (see Table 2). This change would be introduced only after the compulsion's parameters (duration and number of repetitions) have been assessed. An open question enables the participant to state the reasons for pursuing the compulsion (What pushed you to complete the compulsion?). After the phrase "The longer I continue the compulsion ... .", the participant is asked to rate the level of doubt with regard to his or her senses, memory, and attention. We have summarized six redundant statement in a single phrase ("the more I found myself feeling uncertain that it had been conducted properly") and have deleted the item on the lengthening of the duration of the compulsion act (see Table 2). We present an extract of the RADRevised in Appendix A.

Our present findings are in line with the results obtained by Tolin, Abramowitz, Brigidi, and Foa's suggestion (2003) that checking and repeating might be driven by poor tolerance of uncertainty-related distress (see also Sarawgi, Oglesby, \& Cougle, 2013). Tolin, Abramowitz, Brigidi, and Foa (2003) postulated that the pathological doubt was linked to poor tolerance of uncertainty, that is, patients with OCD cannot tolerate ambiguous or uncertain situations. Thus, the need for certainty in the completion of a compulsion may be worth considering as a therapeutic tool. The need to ritualize prompted by uncertainty (i.e., potential danger) might explain the maintenance (or posttreatment recurrence) of OCD in many patients. It will be necessary to establish why a compulsion is performed and evaluate the perceived need for certainty. Rather than focusing on exposure to anxiety associated with the obsession, it may also be of value to expose patients to uncertainty as to whether a compulsion has been performed "properly" (see Tolin et al., 2003 or Lind \& Boschen, 2009, e.g.). Bucarelli and Purdon (2015) suggested exposing people to uncertainty about their compulsions by having them conduct the compulsion once, stop, and wait for the feelings to subside.

Our analysis of the RAD emphasizes that compulsions are hard to eliminate; around $70 \%$ of the OCD patients stopped ritualizing only when they were certain that all sources of danger had been removed (certain compulsions). The effectiveness of CBT must be increased. The development of an approach based on the need for certainty, for example, might be of value in this setting.

\section{ACKNOWLEDGEMENTS}

This study was partially supported by a project grant from the SFR Santé et Société (2014), University Grenoble Alpes.

\section{CONFLICT OF INTEREST}

Martine Bouvard, Nathalie Fournet, Anne Denis, Ouafae Achachi, and Christine Purdon have no conflict of interest with respect to this publication.

\section{ORCID}

Martine Bouvard (D) https://orcid.org/0000-0002-4306-9011

Anne Denis (D) https://orcid.org/0000-0001-6711-9637

\section{REFERENCES}

Abramowitz, J. S., Franklin, M. E., \& Cahill, S. P. (2003). Approaches to common obstacles in the exposure-based treatment of obsessive compulsive disorder. Cognitive and Behavioral Practice, 10, 14-22. https:// doi.org/10.1016/s1077-7229(03)80004-4

Adams, T. G., Riemann, B. C., Wetterneck, C. T., \& Cisler, J. M. (2012). Obsessive beliefs predict cognitive behavior therapy outcome for obsessive compulsive disorder. Cognitive Behaviour Therapy, 41(3), 203-211. https://doi.org/10.1080/16506073.2011.621969

American Psychiatric Association (2013). Diagnostic and statistical manual of mental disorders (fifth edition). Washington, DC: American Psychiatric Publishing. https://doi.org/10.1176/appl.books.9780890425596

Beck, A. T., Ward, C. H., Mendelson, M., Mock, J., \& Erbaugh, J. (1961). An inventory for measuring depression. Archives of General Psychiatry, 4 561-571. https://doi.org/10.1037/t00741-000

Bourque, P., \& Beaudette, D. (1982). Étude psychométrique du questionnaire de dépression de Beck auprès d'un échantillon d'étudiants universitaires francophones [Psychometric study of the Beck Depression Inventory on a sample of French-speaking university students]. Revue Canadienne des Sciences du Comportement, 14, 211-218. https://doi.org/10.1037/h0081254

Bucarelli, B., \& Purdon, C. (2015). A diary study of the phenomenology and persistence of compulsions. Journal of Behavior Therapy and Experimental Psychiatry, 49, 209-215. https://doi.org/10.1016/j.jbtep.2015. 01.001

Coles, M. E., Radomsky, A. S., \& Horng, B. (2006). Exploring the boundaries of memory distrust form repeated checking: Increasing external validity and examining thresholds. Behaviour Research and Therapy, 44, 995-1006. https://doi.org/10.1016/j.brat.2005.08.001

Coughtrey, A. E., Shafran, R., Knibbs, D., \& Rachman, S. J. (2012). Mental contamination in obsessive compulsive disorder. Journal of ObsessiveCompulsive and Related Disorders, 1(4), 244-250. https://doi.org/10. 1016/j.jocrd.2012.07.006

Coughtrey, A. E., Shafran, R., \& Rachman, S. J. (2004). The spontaneous decay and persistence of mental contamination: An experimental analysis. Journal of Behavior Therapy and Experimental Psychiatry, 45, 90-96. https://doi.org/10.1016/j.jbtep.2013.09.001

Cougle, J. R., Goetz, A. R., Fitch, K. E., \& Hawkins, K. A. (2011). Termination of washing compulsions: A problem of internal reference criteria or "not just righ" experience? Journal of Anxiety Disorders, 25, 801-815. https://doi.org/10.1016/j.janxdis.2011.03.019

Diedrich, A., Sckopke, P., Schwartz, C., Schlegl, S., Osen, B., Stierle, C., \& Voderholzer, U. (2016). Change in obsessive beliefs as predictor and mediator of symptom change during treatment of obsessive compulsive disorder-A process-outcome study. BMC Psychiatry, 16, 220. https://doi.org/10.1186/s12888-016-0914-6

Ecker, W., \& Gönner, S. (2008). Incompleteness and harm avoidance in OCD symptoms dimensions. Behaviour Research and Therapy, 46, 895-904. https://doi.org/10.1016/j.brat.2008.04.002 
Hinds, A. L., Woody, E. Z., Van Ameringen, M., Schmidt, L. A., \& Szechtman, H. (2012). When too much is not enough: Obsessive compulsive disorder as a pathology of stopping, rather than starting. PLoS ONE, 7, e30586. https://doi.org/10.1371/journal.pone.0030586

Ishikawa, R., Kobori, O., \& Shimizu, E. (2014). Examining the beliefs that contribute to mental contamination. Journal of Depression and Anxiety, 3(4), 1000166. https://doi.org/10.4172/2167-1044.1000166

Jacoby, R. J., Reuman, L., Blakey, S. M., Jeremiah Hartsock, J., \& Abramowitz, J. S. (2019). What if I make a mistake?: Examining uncertainty-related distress when decisions may harm oneself vs. others. Journal of Obsessive Compulsive and Related Disorders, 20, 50-58. https://doi.org/10.1016/j.jocrd.2017.11.003

Julien, D., Careau, Y., O'Connor, K. P., Bouvard, M., Rhéaume, J., Langlois, F., ... Cottraux, J. (2008). Specificity of belief domains in OCD: Validation of the French version of the Obsessive Beliefs Questionnaire and a comparison across samples. Journal of Anxiety Disorders, 22, 1029-1041. https://doi.org/10.1016/j.janxdis.2007.11.003

Lecrubier, Y., Sheehan, D. V., Weiller, E., Amorim, P., Bonora, I., Harnett Sheehan, K., \& Dunbar, G. C. (1997). The Mini International Neuropsychiatric Interview (MINI). A short diagnostic structured interview: Reliability and validity according to the CIDI. European Psychiatry, 12(5), 224-231. https://doi.org/10.1016/s0924-9338(97)83296-8

Lind, C., \& Boschen, M. J. (2009). Intolerance of uncertainty mediates the relationship between responsibility beliefs and compulsive checking. Journal of Anxiety Disorders, 23, 1047-1052. https://doi.org/10.1016/ j.janxdis.2009.07.005

Mathes, B.M., McDermott, K.A., Okey, S.A., Vasquez, A., Harvey, A.M., Cougle, J.R. (2019). Mental contamination in obsessive compulsive disorder: Associations with contamination symptoms and treatment response. Behavior Therapy, 50, 15-24. https://doi.org/10.1016/j. beth.2018.03.005. Epub 2018 Mar 16.

Nedeljkovic, M., \& Kyrios, M. (2007). Confidence in memory and other cognitive processes in obsessive compulsive disorder. Behaviour Research and Therapy, 45(12), 2899-2914. https://doi.org/10.1016/j. brat.2007.08.001

Purdon, C. (2018). Helping people overcome compulsions. Conference at the University Savoie Mont Blanc.

Purdon, C., \& Bucarelli, B. (2010). Repeated Actions Diary, unpublished manuscript. University of Waterloo.

Rachman, S. (2002). A cognitive theory of compulsive checking. Behaviour Research and Therapy, 40, 635-639. https://doi.org/10.1016/s00057967(01)00028-6

Rachman, S. (2004). Fear of contamination. Behaviour Research and Therapy, 42, 1227-1255. https://doi.org/10.1016/j.brat.2003.10.009

Rachman, S., Radomsky, A., \& Shafran, R. (2008). Safety behavior: A reconsideration. Behaviour Research and Therapy, 46, 163-173. https://doi. org/10.1016/j.brat.2007.11.008

Radomsky, A. S., Gilchrist, P. T., \& Dussault, D. (2006). Repeated checking really does cause memory distrust. Behaviour Research and Therapy, 44, 305-316. https://doi.org/10.1016/j.brat.2005.02.005

Salkovskis, P.M., Shafran, R., Rachman, S., \& Freeston, M.A. (1999). Multiple pathways to inflated responsibility beliefs in obsessive problems: Possible origins and implications for therapy and research. Behaviour Research and Cognitive Therapy, 37(11), 1055-1072. https://doi.org/ 10.1016/s0005-7967(99)00063-7

Sarawgi, S., Oglesby, M. E., \& Cougle, J. R. (2013). Intolerance of uncertainty and obsessive-compulsive symptom expression. Journal of Behavior Therapy and Experimental Psychiatry, 44, 456-462. https:// doi.org/10.1016/j.jbtep.2013.06.001

Sheehan, D. V., Lecrubier, Y., Harnett, K., Amorim, P., Janavs, J., Weiller, E., ... Dunbar, G. C. (1998). The mini-international neuropsychiatric interview (M.I.N.I): The development and validation of a structured diagnostic psychiatric interview for DSM-IV and ICD-10. Journal of Clinical Psychiatry, 59(suppl. 20), 22-33. https://doi.org/10.1016/s0924-9338 (97)83297-x
Starcevic, S. C. V., Berle, D., Brakoulias, V., Sammut, P., Moses, K., Milicevic, D., \& Hannan, A. (2011). Functions of compulsions in obsessive compulsive disorder. Australian and New Zealand Journal of Psychiatry, 45, 449-457. https://doi.org/10.3109/00048674.2011.567243

Szechtman, H., \& Woody, E. (2004). Obsessive-compulsive disorder as a disturbance of security motivation. Psychological Review, 111, 111-127. https://doi.org/10.1007/bf03033239

Thordarson, D. S., Radomsky, R. S., Rachman, S., Shafran, R., Sawchuk, C. N., \& Hakstian, A. R. (2004). The Vancouver Obsessional Compulsive Inventory (VOCl). Behaviour Research and Therapy, 42, 1289-1314. https://doi.org/10.1016/j.brat.2003.08.007

Tolin, D. F., Abramowitz, J. S., Brigidi, B. D., Amir, N., Street, G. P., \& Foa, E. B. (2001). Memory and memory confidence in obsessivecompulsive disorder. Behaviour Research and Therapy, 39, 913-927. https://doi.org/10.1016/s0005-7967(00)00064-4

Tolin, D. F., Abramowitz, J. S., Brigidi, B. D., \& Foa, E. B. (2003). Intolerance of uncertainty in obsessive-compulsive disorder. Journal of Anxiety Disorders, 17, 233-242. https://doi.org/10.1016/s0887-6185(02) 00182-2

Tulving, E. (1985). Memory and consciousness. Canadian Psychologist, 26, 1-12. https://doi.org/10.1037/h0080017

Van den Hout, M., \& Kindt, M. (2003). Repeated checking causes memory distrust. Behaviour Research and Therapy, 41, 301-316. https://doi. org/10.1016/s0005-7967(02)00012-8

Van den Hout, M., \& Kindt, M. (2004). Obsessive compulsive disorder and the paradoxical effects of perseverative behavior on experienced uncertainty. Journal of Behavior Therapy and Experimental Psychiatry, 35, 165-181. https://doi.org/10.1016/j.jbtep.2004.04.007

Van den Hout, M. A., van Dis, E. A. M., van Woudenberg, C., \& van de Groep, I. H. (2019). OCD-like checking in the lab: A meta-analysis and improvement of an experimental paradigm. Journal of ObsessiveCompulsive and Related Disorders, 20, 39-49. https://doi.org/10.1016/ j.jocrd.2017.11.006

Woody, E., \& Szechtman, H. (2011). Adaptation to potential threat: The evolution, neurobiology, and psychopathology of the security motivation system. Neuroscience and Biobehavioral Reviews, 35, 1019-1033. https://doi.org/10.1016/j.neubiorev.2010.08.003

Woody, E. Z., \& Szechtman, H. (2013). A biological security motivation system for potential threats: Are there implications for policy-making? Frontiers in Human Neuroscience, 7(556), 1-5. https://doi.org/10. 3389/fnhum.2013.00556

How to cite this article: Bouvard M, Fournet N, Denis A, Achachi O, Purdon C. A study of the Repeated Actions Diary in patients suffering from obsessive compulsive disorder. Clin Psychol Psychother. 2020;27:228-238. https://doi.org/10. 1002/cpp.2422

\section{APPENDIX A}

\section{A.1 | Excerpts From The Repeated Actions Diary-Revised} DAY ONE - MORNING Date:

Time of diary completion:

Time of episode:

Please complete this diary as soon as possible after a compulsive episode. 
1. What was the obsessional thought, image or fear preceding the compulsive episode?

2. What was the compulsive act?

3. How discomforting was this obsessional thought, image or fear? (circle the number that best applies)

$\begin{array}{llllllll}1 & 2 & 3 & 4 & 5 & 6 & \begin{array}{c}7 \\ \text { not at all } \\ \text { discomforting }\end{array} \\ & & & & & & & \\ \text { discomforting }\end{array}$

4. How awful would the consequences of not performing the compulsion have been? (circle the number that best applies)

\begin{tabular}{lllllll}
1 & 2 & 3 & 4 & 5 & 6 & $\begin{array}{c}7 \\
\text { not at all awful }\end{array}$ \\
\hline
\end{tabular}

5. How certain did you need to be that the compulsive act had been done properly? (circle the number that best applies)

$\begin{array}{llllllll}1 & 2 & 3 & 4 & 5 & 6 & \begin{array}{l}7 \\ \text { needed to be } \\ \text { didn't need to } \\ \text { be certain at all }\end{array} \\ \end{array}$

6. How long did the episode last? hours minutes

7. How many times did you repeat the compulsion within this episode?

8. What pushed you to complete the compulsion? (please use your own words)

Please rate the following statements on a scale of 1 (you strongly disagree) to 7 (you strongly agree). The longer I continue the compulsion:

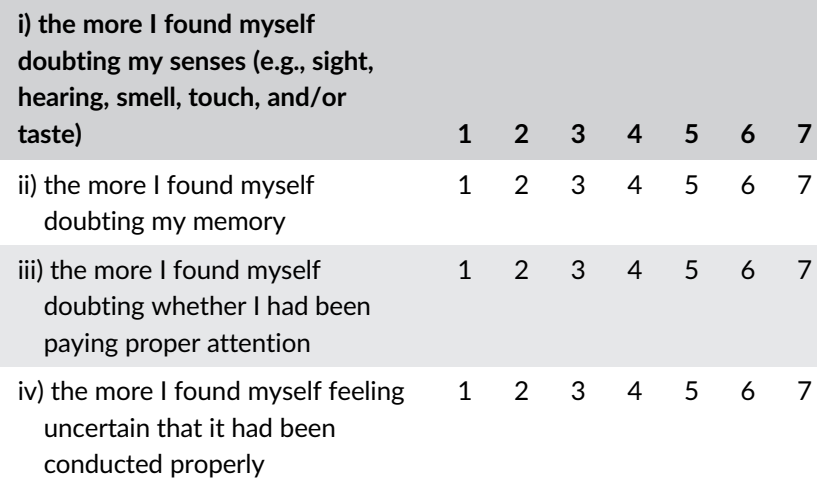

9. How much general relief did you feel upon completion of this compulsive episode? (circle the number that best applies)

$\begin{array}{lllllll}1 & 2 & 3 & 4 & 5 & 6 & 7 \\ \text { no relief at all } & & & & & & \text { complete relief }\end{array}$

10. To what extent did you feel a reduction in guilt upon completion of this compulsive episode? (circle the number that best applies)

$\begin{array}{lllllll}1 & 2 & 3 & 4 & 5 & 6 & 7 \\ \text { no reduction at all } & & & & & & \text { a complete reduction }\end{array}$

11. To what extent did you feel a reduction in responsibility upon completion of this compulsive episode? (circle the number that best applies)

$\begin{array}{lllllll}1 & 2 & 3 & 4 & 5 & 6 & 7 \\ \text { no reduction at all } & & & & & & \text { a complete reduction }\end{array}$

12. To what extend did you feel a reduction in distress upon completion of this compulsive episode? (circle the number that best applies)

$\begin{array}{lllllll}1 & 2 & 3 & 4 & 5 & 6 & 7 \\ \text { no reduction at all } & & & & & & \text { a complete reduction }\end{array}$

13. How did you decide when to stop? (read them all and then rank all that apply)

I felt completely certain it was okay to stop

I felt certain enough that it was okay to stop

I got the right feeling

I had to stop because there was something else I had to do instead

I was too tired to continue

I was interrupted by something or someone 
I knew in my head that it was okay to stop (even if I didn't feel it)

Another reason (please specify)

Someone else reassured me that it was okay to stop 